\title{
Organização do trabalho e adoecimento dos bancários: uma revisão de literatura
}

\author{
Work organization and illness of bank workers: a literature review
}

Elver Andrade Moronte', Guilherme Souza Cavalcanti de Albuquerque ${ }^{\mathbf{1}}$

DOI: $10.1590 / 0103-1104202112817$

\begin{abstract}
RESUMO Este artigo apresenta uma análise de produções científicas das relações entre saúde e trabalho dos trabalhadores bancários, encontradas em teses, dissertações, artigos das literaturas nacional e internacional, produzidos nas línguas portuguesa, inglesa e espanhola, no período de 2008 a 2018. A pesquisa foi feita em bases de dados da Biblioteca Virtual em Saúde e da PubMed, utilizando-se os temas 'bank workers' e 'bank employees', assim como os descritores 'environmental health', 'antidepressive agents', 'occupational diseases', 'stress, psychological', 'depressive disorder', 'burnout, professional', 'cumulative trauma disorders' e os termos livres 'occupational stress', 'stress', ' psychological distress' e 'psychosocial work environment'. Foram encontrados 120 estudos, dos quais, 37 tratavam especificamente do tema. A análise permitiu encontrar uma descrição da visão predominante na literatura acerca das características do trabalho nos bancos que se relacionam ao sofrimento, ao desgaste e ao adoecimento dos trabalhadores. A forma de organização do processo de trabalho no setor bancário se relaciona com o sofrimento e o adoecimento, podendo levar ao suicídio. Apesar da relação estabelecida entre trabalho e adoecimento, a descrição da organização do trabalho é superficial nos estudos, sendo seu aprofundamento importante para a compreensão e a transformação desse panorama.
\end{abstract}

PALAVRAS-CHAVE Saúde do trabalhador. Riscos ocupacionais. Determinantes sociais da saúde. Transtornos mentais.

ABSTRACT This article presents an analysis of scientific production of relations between health and labor of bank workers, found in theses, dissertations, articles in the national and international literature, produced in portuguese, english and spanish, in the period from 2008 to 2018. The study was conducted in data bases of the Virtual Health Library and PubMed, using the themes 'bank workers' and 'bank employees', as well as the descriptors 'environmental health', 'antidepressive agents', 'occupational disease', 'stress, psychological', 'depressive disorder', 'Burnout, professional', 'cumulative trauma disorders' and the free terms 'occupational stress', 'stress', 'psychological distress' and 'psychosocial work environment'. 120 studies were found, of which 37 specifically addressed the topic. The analysis made it possible to find a description of the vision prevalent in the literature about the characteristics of work in banks that are related to workers' suffering, wear and illness. The form of organization of the work process in the banking sector relates to the suffering and illness, which may lead to suicide. Despite the relationship established between work and illness, the description of work organization is superficial in the studies, and its deepening is important for understanding and transformation of this panorama.

1 Universidade Federal do Paraná (UFPR) - Curitiba (PR), Brasil.

elver.moronte@gmail.com
KEYWORDS Occupational health. Occupational risks. Social determinants of health. Mental disorders. 


\section{Introdução}

As instituições bancárias têm passado, nas últimas décadas, por marcantes transformações nos seus processos de trabalho. Essas mudanças têm sido caracterizadas pela maior carga de trabalho e maior quantificação dos resultados do trabalho, possibilitadas, em especial, pela mecanização e informatização, guardando relação com o aumento do adoecimento dos bancários, sendo que os agravos musculoesqueléticos (Lesões por Esforços Repetitivos - LER) e os transtornos mentais estão entre os mais prevalentes nessa população trabalhadora ${ }^{1}$.

No Brasil, a categoria de trabalhadores bancários apresenta alta incidência de adoecimento relacionado ao trabalho. Segundo dados da previdência social, o setor bancário (CNAE 6422) tem uma das mais elevadas taxas de doenças ocupacionais encontradas entre todas as atividades econômicas. No período de 2012 a 2016, por exemplo, os afastamentos por transtornos mentais e comportamentais relacionados ao trabalho somaram 6.763 ocorrências, correspondendo a $12,77 \%$ dos benefícios concedidos por auxílio-doença acidentário (B91). Esses números somente são superados pelos afastamentos concedidos aos trabalhadores da administração pública em geral (CNAE 8411), evidenciando que os bancários constituem o segundo grupo de trabalhadores que mais se afastam por transtornos mentais relacionados ao trabalho ${ }^{2}$.

Segundo os preceitos teóricos do campo da saúde do trabalhador, a compreensão das relações entre trabalho e processo saúde-doença exige, necessariamente, a consideração da determinação social do processo saúde-doença, abordando a promoção da saúde, o sofrer, o adoecer e o morrer das classes e dos grupos sociais inseridos em diferentes processos produtivos ${ }^{3}$, induzidos pelas relações de produção resultantes do estágio de desenvolvimento das forças produtivas em cada momento histórico.
As condições gerais de vida incluem as condições de trabalho como um indicador central de desigualdades sociais. Nesse sentido, ganha especial importância o estudo das condições de trabalho que compreendem as relações de emprego (entre o empregador e o empregado), além dos constrangimentos e das pressões no ambiente físico e na organização do trabalho. Assim, o estudo das condições em que o trabalho é realizado permite maior compreensão dos perfis de adoecimento das diversas frações da classe trabalhadora.

Este estudo tem como objetivo a verificação da produção científica que relaciona as condições do trabalho bancário à identificação dos processos determinantes do adoecimento nesse grupo de trabalhadores, oferecendo um panorama da produção científica e indicando possibilidades de pesquisa nessa área.

\section{Metodologia}

Realizou-se uma revisão integrativa da literatura sobre a produção científica nacional e internacional acerca das relações entre o trabalho nos bancos e a saúde dos trabalhadores bancários. Nesse tipo de revisão, há possibilidade de integração de conceitos, ideias e opiniões presentes nas pesquisas científicas.

A busca dos estudos aconteceu nas bases de dados da Biblioteca Virtual em Saúde (BVS) e PubMed, em meados de 2019. Foram consideradas as publicações em línguas portuguesa, inglesa e espanhola, no período de 10 anos, entre 2008 e 2018. Os termos pesquisados foram 'bank workers' e 'bank employees'. A pesquisa associou os termos escolhidos com os descritores 'environmental health', 'antidepressive agents', 'occupational diseases', 'stress, psychological', 'depressive disorder', 'burnout, professional', 'cumulative trauma disorders' e com os termos livres 'occupational stress', 'stress', 'psychological distress' e 'psychosocial work environment'. 
Realizou-se a análise das produções científicas encontradas em forma de artigos originais, teses e dissertações, considerando-se a seguinte questão norteadora: quais foram as relações encontradas pelas produções científicas latino-americanas nos últimos 10 anos entre o trabalho bancário e a saúde dos trabalhadores?

Foram considerados critérios de inclusão: 1) Estudos realizados na língua portuguesa, inglesa ou espanhola; 2) Estudos publicados entre janeiro de 2008 e dezembro de 2018; 3) Estudos que abordassem a temática do adoecimento relacionado ao trabalho no setor bancário.

A análise foi feita baseada na revisão da literatura selecionada, com reflexões dos autores, após leitura dos resumos (abstracts) e do corpo do texto dos estudos.

\section{Resultados da busca e da seleção}

Ao utilizar a metodologia proposta para a pesquisa, foram encontrados, inicialmente, 120 trabalhos, sendo 86 provenientes da BVS e 44 da PubMed.

Posteriormente, foram excluídos 37 artigos por duplicidade, além de 12 estudos que estavam em língua diferente daquelas definidas (inglês, português e espanhol), resultando em 71 estudos selecionados. Após leitura dos resumos (abstracts) e do corpo do texto, restaram 37 estudos, que foram analisados nesta revisão, já que 34 foram excluídos por não atenderem estritamente à temática estudada.

Figura 1. Fluxograma para resultado da busca de fontes de informação, triagem, seleção e inclusão de artigos

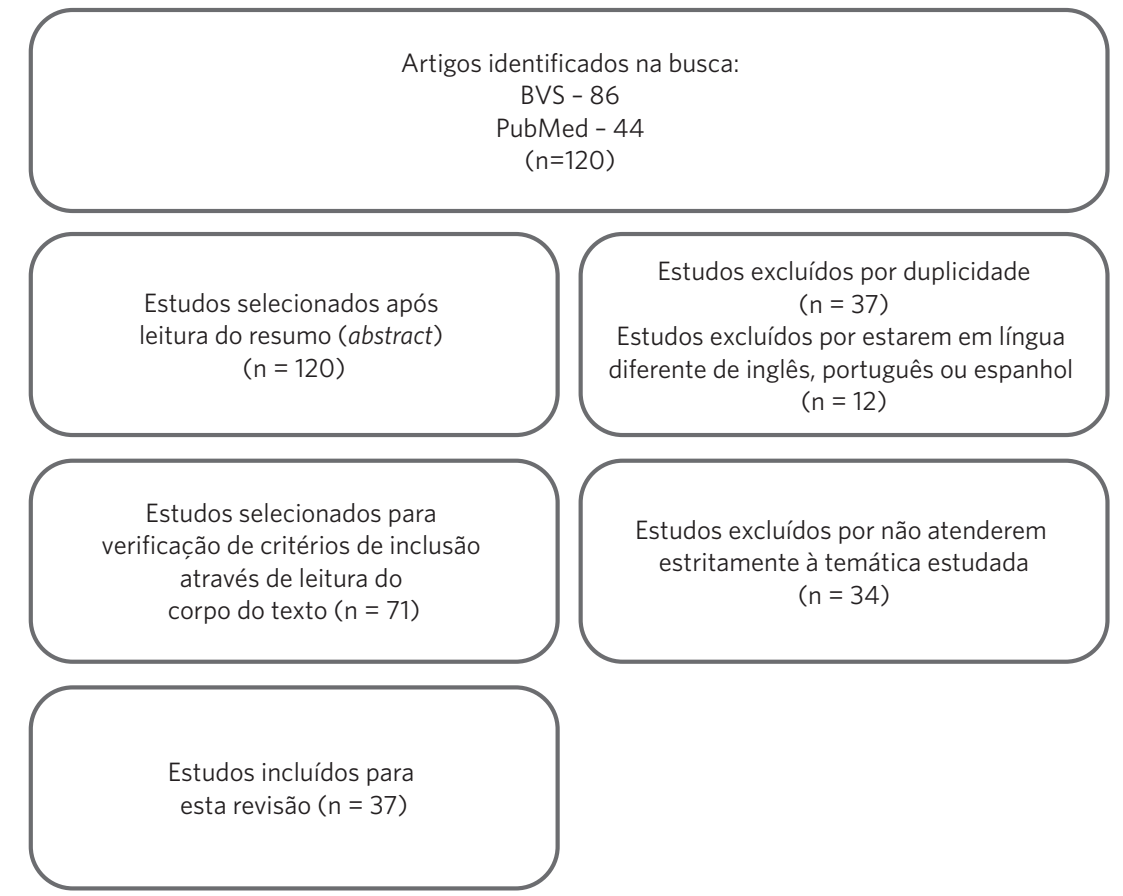

Fonte: Elaboração própria. 


\section{Características dos estudos}

\author{
Conforme se observa no quadro 1, a maior
} parte dos estudos abordou aspectos da organização do trabalho em bancos e sua relação com a saúde dos trabalhadores bancários, sejam no aumento de uso de medicamentos, no adoecimento do sistema musculoesquelético, no aparecimento de doenças crônicas, no sofrimento psíquico e no aparecimento de doenças psíquicas ou até mesmo nos casos de autoviolência (suicídios).

A maioria dos artigos optou por realizar estudos transversais ${ }^{4-36}$, tendo sido mais comum a realização de trabalhos descritivos, com estudo da prevalência de agravos na população bancária e sua relação com as condições de vida e de trabalho. Em dois estudos, os autores optaram pela realização de revisão de literatura ${ }^{37,38}$, e outros três realizaram estudos teóricos ${ }^{39-41}$.

Quadro 1. Características dos estudos incluídos na revisão de literatura, com avaliação de impactos na saúde dos bancários relacionados à organização do trabalho nos bancos

\begin{tabular}{|c|c|c|c|}
\hline & Estudo & Título & Principais resultados \\
\hline 4 & $\begin{array}{l}\text { Geremias et al., } \\
2017\end{array}$ & $\begin{array}{l}\text { Prevalência do diabetes mellitus } \\
\text { associado ao estresse ocupacio- } \\
\text { nal em trabalhadores bancários, } \\
\text { Minas Gerais, Brasil }\end{array}$ & $\begin{array}{l}\text { Relata condições de trabalho nos bancos como fontes de tensão: excesso de carga } \\
\text { horária, intensificação de atividades, pressão por resultados, alta exigência de de- } \\
\text { sempenho, imprevisibilidade das situações, demissões relacionadas ao não cumpri- } \\
\text { mento de metas. }\end{array}$ \\
\hline 5 & $\begin{array}{l}\text { Ferreira e Carva- } \\
\text { Iho, } 2017\end{array}$ & $\begin{array}{l}\text { Saúde do Trabalhador: Avaliação } \\
\text { da Qualidade de Vida no Trabalho } \\
\text { de Bancários }\end{array}$ & $\begin{array}{l}\text { Indica que o trabalho bancário sofreu uma transformação, sendo que atualmente o } \\
\text { trabalhador deve ser um vendedor de produtos, estando submetido a técnicas de } \\
\text { controle do trabalho, principalmente aos sistemas de controle de metas de produti- } \\
\text { vidade. }\end{array}$ \\
\hline 6 & $\begin{array}{l}\text { Jaques e Ziliotto, } \\
2017\end{array}$ & $\begin{array}{l}\text { As contingências do trabalho } \\
\text { bancário: um estudo sobre os } \\
\text { mecanismos de mediação e defe- } \\
\text { sa do sofrimento }\end{array}$ & $\begin{array}{l}\text { Relaciona aspectos do trabalho bancário a influências negativas em sua saúde: redu- } \\
\text { ção do quadro de funcionários, desenvolvimento de tecnologia e modernização dos } \\
\text { processos de trabalho, maior exigência de capacitação dos profissionais, condições } \\
\text { de insegurança salarial e contratual no setor. }\end{array}$ \\
\hline 7 & $\begin{array}{l}\text { Silva e Navarro, } \\
2012\end{array}$ & $\begin{array}{l}\text { Organização do trabalho e saúde } \\
\text { de trabalhadores bancários }\end{array}$ & $\begin{array}{l}\text { Relaciona a reestruturação produtiva com o aumento da produtividade e lucrativida- } \\
\text { de do setor, assim como redução de postos de trabalho, intensificação de seu ritmo, } \\
\text { sobrecarga de tarefas, aumento da pressão e do controle sobre os bancários, com } \\
\text { impactos na saúde dos trabalhadores. }\end{array}$ \\
\hline 8 & $\begin{array}{l}\text { Medeiros et al., } \\
2017\end{array}$ & $\begin{array}{l}\text { Sequestros de bancários e seus } \\
\text { impactos psicossociais e na saúde } \\
\text { do trabalhador }\end{array}$ & $\begin{array}{l}\text { Considera que as modificações na relação capital-trabalho, provenientes da apli- } \\
\text { cação da ideologia neoliberal no setor bancário, geraram precarização nas relações } \\
\text { trabalhistas (redução de salários, aumento das terceirizações e contratos de trabalho } \\
\text { temporários), aumento do ritmo de trabalho (relacionado às metas e aos prazos), } \\
\text { alta carga psicoafetiva (relacionada à exigência de perfeição no desempenho e a } \\
\text { constantes ameaças com relação à carreira). }\end{array}$ \\
\hline 9 & $\begin{array}{l}\text { Silva, Pereira e } \\
\text { Sakurai, } 2008\end{array}$ & $\begin{array}{l}\text { Perfil do absenteísmo em um ban- } \\
\text { co estatal em Minas Gerais: análi- } \\
\text { se no período de } 1998 \text { a } 2003\end{array}$ & $\begin{array}{l}\text { Demonstrou que houve mudança no padrão de adoecimento e afastamento do } \\
\text { trabalho, reduzindo-se os casos de distúrbios musculoesqueléticos e aumentando- } \\
\text {-se os de transtornos mentais. }\end{array}$ \\
\hline 10 & $\begin{array}{l}\text { Picheth e Ichika- } \\
\text { wa, } 2015\end{array}$ & $\begin{array}{l}\text { Uso de ansiolíticos e antidepres- } \\
\text { sivos por bancários: um estudo de } \\
\text { representações sociais }\end{array}$ & $\begin{array}{l}\text { Relaciona o sofrimento e o adoecimento físico e mental à organização do trabalho no } \\
\text { setor bancário (altos níveis de cobrança por produtividade). }\end{array}$ \\
\hline 11 & $\begin{array}{l}\text { Petarli et al., } \\
2015 a\end{array}$ & $\begin{array}{l}\text { Autoavaliação do estado de saúde } \\
\text { e fatores associados: um estudo } \\
\text { em trabalhadores bancários }\end{array}$ & $\begin{array}{l}\text { Atribui um impacto direto sobre a saúde dos bancários às mudanças na organização } \\
\text { e na gestão do trabalho no setor: demissões em massa, automação, terceirização, } \\
\text { reengenharia de negócios, com redução de níveis hierárquicos, precarização do } \\
\text { trabalho e tarefas multifuncionais. }\end{array}$ \\
\hline 12 & $\begin{array}{l}\text { Murofuse NT, } \\
\text { Marziale MHP, } \\
2001\end{array}$ & $\begin{array}{l}\text { Mudanças no trabalho e na vida } \\
\text { de bancários portadores de Le- } \\
\text { sões por Esforços Repetitivos: LER. }\end{array}$ & $\begin{array}{l}\text { Relaciona os transtornos musculoesqueléticos a modificações das condições de } \\
\text { trabalho }\end{array}$ \\
\hline
\end{tabular}


Quadro 1. (cont.)

\begin{tabular}{|c|c|c|c|}
\hline & Estudo & Título & Principais resultados \\
\hline 13 & $\begin{array}{l}\text { Coelho et al., } \\
2018\end{array}$ & $\begin{array}{l}\text { Estresse como preditor da Síndro- } \\
\text { me de Burnout em bancários }\end{array}$ & Relaciona organização do trabalho com o aparecimento de Síndrome de burnout. \\
\hline 14 & $\begin{array}{l}\text { Santos, Siqueira e } \\
\text { Mendes, } 2010\end{array}$ & $\begin{array}{l}\text { Tentativas de Suicídio de Bancá- } \\
\text { rios no Contexto das Reestrutura- } \\
\text { ções Produtivas }\end{array}$ & $\begin{array}{l}\text { Verifica que relacionamentos superficiais no trabalho, excesso ou falta de tarefas, } \\
\text { pouco reconhecimento, desqualificações frequentes e chefias autoritárias estariam } \\
\text { relacionados com casos de ideação suicida e tentativas de autoextermínio. }\end{array}$ \\
\hline 15 & $\begin{array}{l}\text { Santos e Siqueira, } \\
2011\end{array}$ & $\begin{array}{l}\text { Considerações sobre trabalho e } \\
\text { suicídio: um estudo de caso }\end{array}$ & $\begin{array}{l}\text { Relaciona o sofrimento no trabalho com o vínculo afetivo estabelecido entre o ban- } \\
\text { cário e o banco, através do estabelecimento de uma relação de servidão com possi- } \\
\text { bilidade de desencadeamento de perda de identidade e adoecimento. }\end{array}$ \\
\hline 16 & $\begin{array}{l}\text { Soares e Villela, } \\
2012\end{array}$ & $\begin{array}{l}\text { O assédio moral na perspectiva de } \\
\text { bancários }\end{array}$ & $\begin{array}{l}\text { Indica que o assédio moral pode ser considerado como uma forma de gestão que } \\
\text { busca o aumento da produtividade pela intensificação do trabalho. }\end{array}$ \\
\hline 17 & $\begin{array}{l}\text { Scopel, Barros } \\
\text { e Wehrmeister, } \\
2012\end{array}$ & $\begin{array}{l}\text { LER/DORT na terceira década da } \\
\text { reestruturação bancária: novos } \\
\text { fatores associados? }\end{array}$ & $\begin{array}{l}\text { Relaciona o adoecimento dos bancários às estratégias de gestão e aos objetivos e } \\
\text { metas das organizações. }\end{array}$ \\
\hline 18 & $\begin{array}{l}\text { Mergener, Kehrig } \\
\text { e Traebert, } 2008\end{array}$ & $\begin{array}{l}\text { Sintomatologia músculo-esque- } \\
\text { lética relacionada ao trabalho e } \\
\text { sua relação com qualidade de } \\
\text { vida em bancários do Meio Oeste } \\
\text { Catarinense }\end{array}$ & $\begin{array}{l}\text { Relaciona diversos aspectos da organização do trabalho bancário a queixas de dores } \\
\text { ou desconforto no sistema musculoesquelético dos trabalhadores. }\end{array}$ \\
\hline 19 & $\begin{array}{l}\text { Silva e Barreto, } \\
2010\end{array}$ & $\begin{array}{l}\text { Adverse psychosocial working } \\
\text { conditions and minor psychiatric } \\
\text { disorders among bank workers }\end{array}$ & Conclui pela presença de transtornos psiquiátricos menores entre bancários. \\
\hline 20 & $\begin{array}{l}\text { Silva e Barreto, } \\
2012\end{array}$ & $\begin{array}{l}\text { Condições estressantes no traba- } \\
\text { Iho e pior auto avaliação de saúde } \\
\text { entre bancários. }\end{array}$ & $\begin{array}{l}\text { Relaciona a modernização ocorrida no sistema bancário com o aumento da pressão } \\
\text { por tempo, o excesso de demandas de trabalho, conflitos de papel, problemas rela- } \\
\text { cionados à ergonomia, ao aumento dos casos de violência e estresse no trabalho. }\end{array}$ \\
\hline 21 & Paparelli, 2011 & $\begin{array}{l}\text { Grupos de enfrentamento do } \\
\text { desgaste mental no trabalho } \\
\text { bancário: discutindo saúde mental } \\
\text { do trabalhador no sindicato }\end{array}$ & $\begin{array}{l}\text { Relaciona a sobrecarga no trabalho bancário à complexidade das tarefas, exigência } \\
\text { de polivalência, carga psicoafetiva elevada e pressão temporal. }\end{array}$ \\
\hline 22 & $\begin{array}{l}\text { Carrijo e Navarro, } \\
2009\end{array}$ & $\begin{array}{l}\text { LER e planos de demissão volun- } \\
\text { tária: trajetórias de dor e sofri- } \\
\text { mento entre bancários }\end{array}$ & $\begin{array}{l}\text { Relaciona graves repercussões na saúde dos bancários com a reestruturação produ- } \\
\text { tiva desse setor, destacando-se a intensificação do ritmo de trabalho e maior contro- } \\
\text { le e pressão sobre os trabalhadores. }\end{array}$ \\
\hline 23 & $\begin{array}{l}\text { Santos-Júnior, } \\
\text { Mendes e Araujo, } \\
2009\end{array}$ & $\begin{array}{l}\text { Experiência em clínica do trabalho } \\
\text { com bancários adoecidos por } \\
\text { LER/DORT }\end{array}$ & $\begin{array}{l}\text { Relacionou o adoecimento de bancários com a organização do trabalho nos bancos, } \\
\text { destacando a redução do número de funcionários, a política de metas de produtivi- } \\
\text { dade, o estímulo à competição e a instabilidade no emprego. }\end{array}$ \\
\hline 24 & $\begin{array}{l}\text { Ferreira e Seidl, } \\
2009\end{array}$ & $\begin{array}{l}\text { Mal-estar no trabalho: análise } \\
\text { da cultura organizacional de um } \\
\text { contexto bancário brasileiro }\end{array}$ & $\begin{array}{l}\text { Identificou como causadores do mal-estar no trabalho aspectos da organização do } \\
\text { trabalho como baixa expectativa na carreira, salários baixos, distribuição das tarefas } \\
\text { e excesso de controle das instituições sobre os trabalhadores. }\end{array}$ \\
\hline 25 & $\begin{array}{l}\text { Paiva e Borges, } \\
2009\end{array}$ & $\begin{array}{l}\text { O ambiente de trabalho no setor } \\
\text { bancário e o bem-estar }\end{array}$ & $\begin{array}{l}\text { Relaciona a presença de adoecimento (depressão e tensão emocional) com a organi- } \\
\text { zação e as relações de trabalho. }\end{array}$ \\
\hline 26 & Kan e Yu, 2016 & $\begin{array}{l}\text { Occupational Stress, Work-Family } \\
\text { Conflict and Depressive Symp- } \\
\text { toms among Chinese Bank Em- } \\
\text { ployees: The Role of Psychological } \\
\text { Capital }\end{array}$ & $\begin{array}{l}\text { Encontrou altos níveis de transtornos do humor (depressão) em amostragem de } \\
1.239 \text { trabalhadores bancários chineses, indicando que pode haver relação com } \\
\text { aspectos do trabalho bancário no país (altas cargas de trabalho, necessidade de } \\
\text { concentração nas tarefas, necessidade de esconder as emoções negativas e de } \\
\text { responder a várias demandas dos clientes). }\end{array}$ \\
\hline 27 & $\begin{array}{l}\text { Snorradóttir et al., } \\
2013\end{array}$ & $\begin{array}{l}\text { Financial crisis and collapsed } \\
\text { banks: psychological distress and } \\
\text { work related factors among sur- } \\
\text { viving employees - a nation-wide } \\
\text { study }\end{array}$ & $\begin{array}{l}\text { Indica que houve, após a crise financeira mundial de } 2008 \text {, redução de salários, } \\
\text { transferências de trabalhadores para outros departamentos, perda de postos de tra- } \\
\text { balho e reestruturação de processos nos bancos, ocasionando estresse psicológico } \\
\text { durante as mudanças organizacionais. }\end{array}$ \\
\hline
\end{tabular}




\section{Quadro 1. (cont.)}

\begin{tabular}{|c|c|c|c|}
\hline & Estudo & Título & Principais resultados \\
\hline 28 & $\begin{array}{l}\text { Moraes e Bastos, } \\
2017\end{array}$ & $\begin{array}{l}\text { Os Sintomas de LER/DORT: um } \\
\text { Estudo Comparativo entre Bancá- } \\
\text { rios com e sem Diagnóstico }\end{array}$ & Relaciona o adoecimento musculoesquelético à carga de trabalho dos bancários. \\
\hline 29 & $\begin{array}{l}\text { Gaviraghi et al., } \\
2016\end{array}$ & $\begin{array}{l}\text { Medicalização, uso de substâncias } \\
\text { e contexto de trabalho em bancá- } \\
\text { rios do Rio Grande do Sul, Brasil }\end{array}$ & $\begin{array}{l}\text { Verificou uso de psicofármacos em níveis elevados, quando comparado com a popu- } \\
\text { lação em geral, indicando que essa medicalização pode ser relacionada a uma estra- } \\
\text { tégia de enfrentamento das dificuldades encontradas no trabalho. }\end{array}$ \\
\hline 30 & Valente, 2014 & $\begin{array}{l}\text { Depressão e esgotamento profis- } \\
\text { sional em bancários }\end{array}$ & $\begin{array}{l}\text { Verificou-se presença de alto esforço desprendido nas atividades de trabalho, alta } \\
\text { demanda de trabalho e baixo controle, assim como comprometimento excessivo e } \\
\text { desequilíbrio esforço-recompensa no trabalho, atribuindo-se risco aumentado para } \\
\text { desencadeamento de transtornos do humor, como depressão. }\end{array}$ \\
\hline 31 & $\begin{array}{l}\text { Bittencourt e } \\
\text { Vinholes, } 2013\end{array}$ & $\begin{array}{l}\text { Estimativa do risco para diabetes } \\
\text { mellitus tipo } 2 \text { em bancários da ci- } \\
\text { dade de Tubarão, estado de Santa } \\
\text { Catarina, Brasil }\end{array}$ & $\begin{array}{l}\text { Considera que os bancários estariam submetidos a constantes situações de estresse } \\
\text { no trabalho, relacionando-as a um maior risco de desenvolvimento de diabetes. }\end{array}$ \\
\hline 32 & $\begin{array}{l}\text { Hartwig, Macha- } \\
\text { do e Hallal, } 2009\end{array}$ & $\begin{array}{l}\text { Indicadores antropométricos e } \\
\text { nível de atividade física de funcio- } \\
\text { nários de banco }\end{array}$ & $\begin{array}{l}\text { Estudo com } 55 \text { bancários encontrou sobrepeso em 55\% dos trabalhadores, além de } \\
13 \% \text { com obesidade. O nível de sedentarismo atingiu 69\% da amostra. }\end{array}$ \\
\hline 33 & $\begin{array}{l}\text { Salaroli et al., } \\
2013\end{array}$ & $\begin{array}{l}\text { Prevalence of metabolic syndro- } \\
\text { me and related factors in bank } \\
\text { employees according to different } \\
\text { defining criteria, Vitória/ES, Brazil }\end{array}$ & $\begin{array}{l}\text { Constatou aumento das taxas de obesidade, sobrepeso, hipertensão arterial, relacio- } \\
\text { nando às características do trabalho bancário. }\end{array}$ \\
\hline 34 & $\begin{array}{l}\text { Konradi el al., } \\
2011\end{array}$ & $\begin{array}{l}\text { Prevalence of metabolic syndrome } \\
\text { components in a population of } \\
\text { bank employees from St. Peters- } \\
\text { burg, Russia }\end{array}$ & $\begin{array}{l}\text { Estudo com } 1.561 \text { bancários russos relaciona altas taxas de síndrome metabólica às } \\
\text { características do trabalho. Também foram encontradas taxas altas de obesidade } \\
\text { abdominal e hipertensão arterial. }\end{array}$ \\
\hline 35 & $\begin{array}{l}\text { Momin et al., } \\
2012\end{array}$ & $\begin{array}{l}\text { Study of socio-demographic fac- } \\
\text { tors affecting prevalence of hyper- } \\
\text { tension among bank employees of } \\
\text { Surat City }\end{array}$ & $\begin{array}{l}\text { Em estudo com } 1.493 \text { bancários na Índia, encontrou-se prevalência de hipertensão } \\
\text { arterial em 30,4\% dos trabalhadores. }\end{array}$ \\
\hline 36 & $\begin{array}{l}\text { Petarli et al., } \\
2015 b\end{array}$ & $\begin{array}{l}\text { Estresse ocupacional e fatores } \\
\text { associados em trabalhadores } \\
\text { bancários, Vitória - ES, Brasil }\end{array}$ & $\begin{array}{l}\text { Estimou-se um risco intermediário ao estresse ocupacional, utilizando-se o instru- } \\
\text { mento de avaliação Job Stress Scale. }\end{array}$ \\
\hline 37 & $\begin{array}{l}\text { Marques e Gion- } \\
\text { go, } 2016\end{array}$ & $\begin{array}{l}\text { Trabalhadores bancários em sofri- } \\
\text { mento: uma análise da literatura } \\
\text { nacional }\end{array}$ & $\begin{array}{l}\text { A vivência de sofrimento entre bancários foi relacionada a insegurança, pressões } \\
\text { de superiores, assédio moral. O adoecimento do sistema musculoesquelético foi } \\
\text { considerado uma das principais formas de vivência de sofrimento nessa categoria } \\
\text { profissional. }\end{array}$ \\
\hline 38 & Mello et al., 2011 & $\begin{array}{l}\text { Considerações clínicas sobre a } \\
\text { psicoterapia cognitivo-comporta- } \\
\text { mental de bancários com Trans- } \\
\text { torno de Estresse Pós-Traumático }\end{array}$ & $\begin{array}{l}\text { Relata que os assaltos são comuns na atividade dos bancários, sendo esse um fator } \\
\text { potencial para o desenvolvimento de transtornos mentais como o estresse pós- } \\
\text {-traumático. }\end{array}$ \\
\hline 39 & $\begin{array}{l}\text { Martinez e Ma- } \\
\text { tiello Júnior, } 2012\end{array}$ & $\begin{array}{l}\text { Os limites da ginástica laboral } \\
\text { para compreensão dos determi- } \\
\text { nantes de saúde de trabalhadores } \\
\text { bancários }\end{array}$ & $\begin{array}{l}\text { Indica que as práticas de prevenção de adoecimento, como a adoção de ginástica } \\
\text { laboral, podem servir para mascarar os determinantes da degradação das condições } \\
\text { de vida e de saúde dos bancários, podendo, inclusive, colaborar para a intensificação } \\
\text { da exploração capitalista. }\end{array}$ \\
\hline 40 & $\begin{array}{l}\text { Oltramari, Grisci e } \\
\text { Weber, } 2011\end{array}$ & $\begin{array}{l}\text { Carreira e relações familiares: } \\
\text { dilemas de executivos bancários }\end{array}$ & $\begin{array}{l}\text { Relaciona as exigências do trabalho bancário com sofrimento e adoecimento dos } \\
\text { trabalhadores. }\end{array}$ \\
\hline 41 & Pavão, 2013 & $\begin{array}{l}\text { La lucha de los sindicatos de } \\
\text { bancarios de Brasil contra el acoso } \\
\text { moral }\end{array}$ & $\begin{array}{l}\text { Relaciona o uso da tecnologia no setor bancário, tendo como uma de suas consequ- } \\
\text { ências a redução intensa de postos de trabalho. }\end{array}$ \\
\hline
\end{tabular}

Fonte: Elaboração própria. 


\section{A (re)estruturação do trabalho bancário}

O permanente processo de revolucionamento das forças produtivas, em busca da melhoria da produtividade, proporcionou, desde meados do século XX, significativas inovações tecnológicas que trouxeram maior eficiência para o processo produtivo. Um mesmo trabalhador, amparado na nova tecnologia, passou a realizar operações que antes exigiam vários trabalhadores. Instituiu-se, assim, o que ficou conhecido como reestruturação produtiva.

Os processos de trabalho passaram a ser, predominantemente, marcados pela flexibilização, destronando os modelos de caráter fordista/taylorista, de produção em massa de mercadorias uniformes, por meio de operações fragmentadas e repetitivas realizadas por diferentes trabalhadores.

No mercado de trabalho, as consequências se expressaram pela predominância dos vínculos precários e pelo avanço do emprego temporário, com a contratação de acordo com o aumento da demanda de produção e a ágil demissão diante da redução da necessidade de produção das mercadorias.

Facilitado pelo alto índice de desemprego, assim gerado e com amparo na desregulamentação do trabalho, multiplicaram-se os contratos temporários e viabilizou-se grande redução dos salários.

A globalização dos mercados, o aumento da competitividade entre empresas, a reestruturação produtiva, as inovações tecnológicas e sócio-organizacionais e a flexibilização das relações de trabalho, entre outros fenômenos contemporâneos, afetaram o mundo do trabalho de maneira a gerar impactos negativos na saúde dos trabalhadores.

Essas consequências ocorreram não somente nos trabalhos voltados à produção de mercadorias, como os da indústria, mas, também, em serviços como os bancários.

Medeiros et al. ${ }^{\mathbf{8}}$ afirmam que as modificações na relação capital-trabalho, tributárias da ideologia neoliberal, acarretaram intensa redução de direitos e relações de emprego menos vantajosas aos bancários, com redução de salários, aumento das terceirizações e a instituição de contratos temporários.

Snorradóttir et al. ${ }^{27}$ verificaram que, após a crise financeira mundial de 2008 , houve redução de salários, transferências de trabalhadores para outros departamentos, perda de postos de trabalho e reestruturação de processos, ocasionando estresse psicológico durante as mudanças organizacionais.

As condições laborais, advindas da nova organização e da modernização dos processos de trabalho, são citadas por diversos autores, que demonstram as repercussões negativas, em especial, para a saúde mental dos bancários.

As mudanças ocorridas no processo de trabalho bancário incluem diversos elementos. $\mathrm{O}$ trabalho, ou a própria atividade, em si, passa a ser marcado pela intensificação da exploração obtida por diversas formas de pressão sobre o trabalhador. Mudanças nos meios de trabalho materializam-se, em especial, na adoção de novas tecnologias produtivas, às quais os bancários são forçados a se adaptar. Em algumas situações, a própria finalidade do trabalho tem-se alterado, exigindo do bancário maior atuação como vendedor de produtos.

A nova organização do trabalho nos bancos propiciaria pressões temporais quanto ao ritmo de trabalho, como metas e prazos, influenciando a dinâmica de trabalho e reduzindo os limites de autonomia do trabalhador. Haveria, também, alta carga psicoafetiva relacionada às estratégias organizacionais, como exigência de perfeição no desempenho e constantes ameaças com relação à carreira ${ }^{8}$.

Geremias et al. 4 também consideram que as condições de trabalho nos bancos expõem os trabalhadores a várias fontes de tensão, como excesso de carga horária, intensificação de atividades, pressão por resultados, alta exigência de desempenho, além da imprevisibilidade e do receio das demissões relacionadas ao não cumprimento de metas.

Jaques e Ziliotto ${ }^{6}$ indicam que a redução do quadro de funcionários, associada ao 
incremento do uso da tecnologia, à modernização dos processos de trabalho, assim como a uma maior exigência de capacitação dos profissionais, tem influenciado negativamente a saúde dos bancários. Os autores relatam que esse panorama se agrava com as condições de insegurança salarial e contratual no setor, coincidindo com os achados de Silva e Navarro ${ }^{7}$.

Silva, Pinheiro e Sakurai ${ }^{9}$ apontam, também, que há relação direta entre a organização do trabalho e as morbidades em um banco pesquisado (distúrbios mentais e comportamentais), pois os agravos mais prevalentes estavam ligados à forma com que o trabalho se organizava.

Segundo Picheth e Ichikawa ${ }^{10}$, as pesquisas sobre os bancários incluem essa profissão entre as "profissões mais estressantes". Os autores também relacionam esse fato a mudanças geradas no trabalho e em seu contexto. A presença de alta cobrança, o estabelecimento de metas de produtividade extremamente elevadas, o controle estrito sobre os tempos de trabalho e os consequentes altos níveis de estresse são apontados como relacionados ao sofrimento e ao adoecimento físico e mental dessa população de trabalhadores.

Martinez e Júnior ${ }^{39}$ também consideram que as mudanças organizacionais mais recentes no setor bancário são responsáveis pela intensificação da exploração humana e pela deterioração das condições de vida e saúde dos trabalhadores. Observam, ainda, que a adoção de estratégias de enfrentamento do adoecimento, nessa categoria, como a ginástica laboral para prevenção de distúrbios musculoesqueléticos, é insuficiente, diante da necessidade de transformação das condições de trabalho, já que a degradação da vida dos bancários seria devida à exploração inerente ao modo de produção capitalista. Os autores apontam que essas práticas de prevenção de adoecimento, como a adoção de ginástica laboral, podem servir para mascarar os determinantes da degradação das condições de vida e de saúde dos bancários, podendo, inclusive, colaborar para a intensificação da exploração capitalista. Entendem, também, que essas práticas servem para reduzir as tensões entre o capital e o trabalho, por despertarem nos trabalhadores uma sensação de 'cuidado' e 'proteção'.

Petarli et al."11 atribuem, também, responsabilidade sobre o impacto direto sobre a saúde dos bancários às mudanças na organização e na gestão do trabalho no setor, marcadas pela precarização, por demissões em massa, automação, terceirização, reengenharia de negócios, com redução de níveis hierárquicos, e instituição de tarefas multifuncionais. Para os gerentes, por exemplo, verifica-se o aumento de encargos e responsabilidades, gerando maior pressão emocional. Os autores também identificaram, como problema, a adoção de metas, importante fator estressor e de insatisfação no trabalho:

\begin{abstract}
Além disso, as estratégias mercadológicas dos bancos impõem a estes trabalhadores, metas geralmente estabelecidas por níveis hierárquicos superiores, e não raramente consideradas inatingíveis, incluindo a necessidade de venda de produtos financeiros, o que aumenta consideravelmente a pressão imposta a estes trabalhadores, que nem sempre, apesar de todas as demandas a serem cumpridas, possuem controle suficiente sobre a forma de execução dos trabalhos ${ }^{11(3931)}$
\end{abstract}

A questão das frequentes incorporações de novas tecnologias, citada anteriormente no estudo de Jaques e Ziliotto ${ }^{6}$, como aspecto deletério para a saúde, é reiteradamente referida na literatura pesquisada, como geradora de dificuldades expressivas aos trabalhadores, forçados a se adaptarem a modificações no processo de trabalho, com prejuízo ao desempenho e maior possibilidade de desgaste e adoecimento.

Murofuse e Marziale ${ }^{\mathbf{1 2}}$ também concluem que a automação, a introdução de novas tecnologias e as mudanças na organização do trabalho no setor bancário estariam relacionadas ao adoecimento dessa parcela da classe trabalhadora. 
Carrijo e Navarro 22 também estabelecem uma relação entre a introdução de novas tecnologias no setor bancário e o adoecimento dos trabalhadores. A automatização e a informatização, com a consequente intensificação do ritmo de trabalho, da pressão e do controle sobre os trabalhadores, trazem, segundo os autores, graves repercussões para sua vida e sua saúde.

Segundo Pavão41, a tecnologia modificou particularmente o trabalho nos bancos, também porque o autosserviço bancário faz com que o próprio cliente resolva problemas que antes eram de atribuição dos bancários, levando à redução drástica de postos de trabalho no setor. Assim, o capital, por meio da tecnologia, obteve uma redução de 800.000 postos de trabalho bancário, em 1980, para 400.000, no ano 2000. O autor verifica, ainda, que as chamadas "formas modernas de gestão", marcadas pela reestruturação produtiva, reengenharia, qualidade total, entre outras, provocaram insegurança e ansiedade nos trabalhadores. Outro problema verificado por Pavão é o "culto ao individualismo", em que um colega vê o outro como um adversário a ser eliminado, onde o sucesso individual substitui a cooperação na realização das tarefas. Também constata que a organização do trabalho bancário, ao fixar metas de produção sem considerar a visão dos trabalhadores, promove uma violência psicológica no trabalho.

Em estudo sobre burnout em bancários, Coelho et al. ${ }^{13}$ reconhecem que situações como cumprimento de metas, obrigações de venda de pacotes bancários, agressões provenientes dos clientes, excesso de jornada de trabalho e mecanismos de avaliação de desempenho estão relacionadas ao adoecimento dos trabalhadores.

Santos, Siqueira e Mendes ${ }^{14}$ estudaram a degradação das condições de saúde física e mental de bancários. As vivências de sofrimento, em relatos desses trabalhadores, estariam relacionadas ao que os autores chamaram de circunstâncias estressantes: relacionamentos superficiais no trabalho, excesso ou falta de tarefas, pouco reconhecimento, desqualificações frequentes e chefias autoritárias.

Segundo o estudo, o sofrimento relacionado ao trabalho exerce influência importante nos casos de ideação suicida e tentativas de autoextermínio, já que as pressões e imposições feitas, assim como a desqualificação dos trabalhadores,

São de tal maneira introjetadas que inviabilizam o confronto do sofrimento, restando a morte como a alternativa que se anuncia como modo radical de denunciar a dor moral contra a opressão ${ }^{14}$.

Por fim, concluem que as formas de gestão do trabalho bancário estão intimamente relacionadas à sua degradação, podendo abrir caminho para a ocorrência de casos de suicídio:

As novas formas de gestão do trabalho desestabilizam e desestruturam o coletivo e, com isso, minam o espaço político e democrático do trabalho, a possibilidade de construção de estratégias para transformar a realidade, exigindo cada vez mais dos trabalhadores novas formas de resistência e de mobilização para fazer face a estas condições. Infelizmente, em muitas oportunidades, a luta é vencida pela patologia, sendo o suicídio uma alternativa que se apresenta para erradicar o sofrimento que, aos poucos, se foi tornando insuportável e imbatível diante da fragilidade e vulnerabilidade que a solidão provoca no ser humano ${ }^{14(936)}$.

Santos, Siqueira e Mendes ${ }^{\mathbf{1 4}}$ também abordam a questão da organização do trabalho, afirmando que a padronização dos comportamentos e das rotinas, que promove a desapropriação do saber, pode acarretar efeitos negativos na saúde física e psíquica dos trabalhadores, sugerindo que há relação entre o trabalho e quadros de sofrimento, perda de identidade e adoecimento que levem a casos de ideação suicida.

Em pesquisa com bancários da região norte do Brasil, Soares e Villela ${ }^{16}$ verificaram 
a relação do sofrimento mental dos bancários com a prática do assédio moral. $\mathrm{O}$ assédio moral é uma forma de pressão diretamente relacionada à política de gestão do banco, inserida em um contexto socioeconômico no qual "o capital impõe novas formas de ultrapassar a produção, intensificando o trabalho e atribuindo-lhe um novo sentido"16(211).

As práticas provenientes da nova forma de organização e gestão do trabalho levam a situações como pressão, isolamento físico, isolamento psicológico, descuido com as necessidades do outro, humilhação, desrespeito, dominação, agressão, perseguição, ofensa e todo tipo de conduta que afete a existência do indivíduo que trabalha. As autoras consideram que essa situação, tendo como objetivo impulsionar o alcance de metas, resultados e lucro, beneficia as instituições financeiras e prejudica a saúde dos trabalhadores.

Em estudo transversal que considerou 356 trabalhadores de 27 agências bancárias em Porto Alegre, RS, Scopel, Oliveira e Wehrmeister ${ }^{17}$ também concluem que deve ser dada maior atenção à organização do trabalho, às estratégias de gestão e de constituição de objetivos e metas das organizações, pois esses aspectos estão intimamente relacionados com o adoecimento no setor. A investigação de casos suspeitos de LER/Dort (Distúrbios Osteomusculares Relacionados ao Trabalho) evidenciou que o cargo exercido no banco não interferia no desfecho de adoecimento musculoesquelético, ao contrário de estudos anteriores, que indicavam as funções de caixa e escriturário como as em que havia maior incidência desses agravos. Isso pode ser explicado pelo fato de que, após as reestruturações do trabalho bancário, houve redução daquelas atividades de entrada de dados. Por outro lado, a maioria dos bancários passou a realizar a venda de produtos e serviços financeiros, submetidos a maior cobrança de metas e maiores exigências de produtividade.

Segundo Ferreira e Carvalho ${ }^{5}$, a transformação do bancário em vendedor de produtos, submetendo-o a técnicas de controle, especialmente pelos sistemas de metas de produtividade, constitui uma das mudanças mais relevantes.

Mergerner, Kehrig e Traebert ${ }^{\mathbf{1 8}}$ fizeram, também, associações entre diversos aspectos da organização do trabalho bancário com queixas de dores ou desconforto no sistema musculoesquelético. A vivência de sofrimento entre bancários foi relacionada a insegurança, pressões de superiores e assédio moral.

Para Silva e Barreto ${ }^{19}$, a modernização ocorrida no sistema bancário trouxe para seus trabalhadores o aumento da pressão por tempo, o excesso de demandas de trabalho, os conflitos de papel, problemas relacionados à ergonomia, além do aumento dos casos de violência e estresse no trabalho.

A elevada prevalência, entre os bancários, de autoavaliação do estado de saúde como ruim foi relacionada à exposição a fatores psicossociais adversos no trabalho, em outro estudo de Silva e Barreto ${ }^{20}$.

Em estudo sobre a saúde dos bancários, Paparelli21 verificou a presença de sobrecarga relacionada ao trabalho, com destaque para a complexidade das atividades, a exigência de polivalência, as elevadas cargas psicoafetivas (exigência de exacerbado autocontrole emocional e de perfeição em desempenho, altos níveis de responsabilidade, insegurança sobre a manutenção do emprego e as perspectivas de carreira) e pressão temporal.

A competição entre os trabalhadores dos bancos é apontada por Oltramari, Grisci e Weber ${ }^{40}$ como importante fator de adoecimento. Os casos ali estudados mostraram que ela estava relacionada com a alta exigência de disponibilidade dos executivos para suas atividades profissionais, com prejuízo para seu descanso, sono e convívio familiar e social. As consequências podem manifestar-se pelo comprometimento das relações familiares, sofrimento e adoecimento.

Santos Júnior, Mendes e Araujo ${ }^{23}$ constataram que o processo de adoecimento, em 13 bancários avaliados, estava relacionado à organização do trabalho, em especial, com 
"a redução do quadro de funcionários, o incremento das políticas de metas, o estímulo à competição entre pares e a instabilidade do emprego"23(624).

Em estudo com 1.164 bancários, Ferreira e Seidl24 identificaram mal-estar no trabalho com insatisfação proveniente do ambiente organizacional (fatores físicos e sociais, baixa perspectiva na carreira, salário baixo e incompatível com as responsabilidades) e do modo de gestão do trabalho (distribuição desigual de tarefas, excesso de controle). Também verificaram prejuízo no envolvimento com o trabalho devido à presença de tarefas repetitivas, tratamento desigual e relações conflituosas entre funcionários. A falta de reconhecimento, por parte das chefias e do banco, dos serviços prestados foi relacionada como um problema.

Já o estudo de Paiva e Borges 25, com 200 bancários, estabeleceu correlações entre depressão e tensão emocional com a organização e as relações do trabalho.

Pesquisa com bancários chineses considerou que seu estresse se deve às características do trabalho, que exige concentração intensa, esconder as emoções negativas e responder aos questionamentos dos clientes. Além disso, a competição entre bancos levou a aumento da carga de trabalho, sem que houvesse recompensas aos trabalhadores, como crescimento na carreira, estabilidade, respeito e reconhecimento ${ }^{26}$.

Santos e Siqueira ${ }^{15}$ relacionam, ainda, o sofrimento no trabalho bancário a um vínculo afetivo estabelecido pelo empregado com a empresa.

Nesse processo, o trabalhador incorpora elementos do imaginário corporativo como razão de sua existência. O trabalhador, denominado agora 'colaborador', é incentivado a disponibilizar-se integralmente aos desejos do empregador, como que para merecer a dádiva de manter-se empregado. Essa relação de servidão pode levar a quadros de perda de identidade e adoecimento.

Em muitos casos, o trabalhador desenvolve relações afetivas com seu trabalho, de forma que a organização se torna o único núcleo de sua vida. As exigências impostas pelas empresas são de trabalhadores dedicados, flexíveis e atualizados, que sejam 'obcecados pelo sucesso'. Os indivíduos devem estar, portanto, inteiramente comprometidos com o projeto institucional.

\section{Adoecimento dos bancários pelo trabalho}

O adoecimento do sistema musculoesquelético foi considerado uma das principais formas de vivência de sofrimento para essa categoria profissional, de acordo com Marques e Giongo ${ }^{37}$.

Carrijo e Navarro ${ }^{22}$, em pesquisa realizada em 2002 em um banco estatal de Ribeirão Preto, SP, consideraram as LER um grave problema de saúde pública, em especial, para os bancários. Santos Júnior, Mendes e Araujo ${ }^{23}$ constataram aumento significativo da incidência de LER/Dort no Brasil, relatando que foram afastados 25.080 bancários com esse agravo entre 2000 e 2005 , o que significou um gasto de 981,4 milhões de reais em concessão de benefícios previdenciários.

Para Moraes e Bastos ${ }^{\mathbf{2 8}}$, as LER/Dort estariam relacionadas à carga de trabalho dos bancários, indicando que haveria necessidade de se promoverem melhorias na quantidade e na qualidade das pausas no trabalho.

Silva, Pinheiro e Sakurai ${ }^{9}$, analisando o perfil do absenteísmo em um banco estatal em Minas Gerais, no período de 1998 a 2003, verificaram, no entanto, que a incidência de agravos musculoesqueléticos reduziu, enquanto o número de transtornos mentais aumentou, o que sugere uma mudança no perfil epidemiológico dessa categoria, causado pelas modificações do trabalho no setor.

Estudo de Coelho et al. ${ }^{13}$ relacionou o elevado nível de demanda, baixos controle e apoio social, a elevados níveis de exaustão emocional e despersonalização em bancários, assim como baixo nível de realização profissional, sugerindo que tais aspectos estariam relacionados ao aparecimento de Síndrome de burnout. 
Em revisão sobre a ocorrência de estresse pós-traumático em bancários, Mello et al. ${ }^{38}$ constataram que muitos dos trabalhadores vivenciam, no banco, várias situações de violência, em especial, relacionadas a assaltos. Muitas vezes, mesmo após a ocorrência do assalto, a agência mantém seu funcionamento, obrigando os funcionários a trabalhar sob o impacto da situação traumática que acabaram de vivenciar, o que aumenta a chance de desenvolverem esse transtorno.

Santos e Siqueira ${ }^{15}$, em um estudo de caso, estabelecem relações entre elementos da organização do trabalho e um caso de suicídio de um bancário, corroborando o resultado da pesquisa de Santos, Siqueira e Mendes ${ }^{\mathbf{1 4}}$, que aponta alta incidência de ideação e tentativa de suicídio entre os bancários.

Picheth e Ichikawa ${ }^{10(356)}$ demonstram, também, que

A classe de bancários apresenta alta incidência de Síndrome de Burnout, transtorno grave de tensão emocional de caráter depressivo relacionado ao trabalho em que o estresse leva o indivíduo ao esgotamento por exaustão.

As citadas autoras verificaram que, como consequência das mudanças negativas nas relações de emprego e condições de trabalho nas instituições bancárias, os trabalhadores em sofrimento mental recorrem, preferencialmente, ao uso de ansiolíticos e antidepressivos como tentativa de alívio. Os trabalhadores que não lançaram mão desses fármacos relataram uso de álcool, anti-inflamatórios e relaxantes musculares para alívio de desconforto e sofrimento.

Gaviraghi et al. ${ }^{29}$ também constataram elevada prevalência do uso de psicofármacos $(26,3 \%)$ em uma população estudada (1.117 bancários), quando comparada com a população em geral (menor que $12 \%$ ), o que sugeriu que o trabalho bancário é um 'potencializador de mal-estar', gerando sofrimento psíquico e maior risco de adoecimento para os trabalhadores. Observaram, também, que, como estratégia de enfrentamento das dificuldades encontradas, os bancários lançam mão do uso de substâncias psicoativas, recorrendo à medicalização.

Kan e $\mathrm{Yu}^{26}$ estudaram 1.239 bancários chineses, verificando relação entre exaustão emocional e despersonificação, características do burnout, com a sobrecarga e o excesso de comprometimento com o trabalho. Foram encontrados altos níveis de transtornos do humor (depressão), indicando que pode haver relação com aspectos do trabalho bancário no País (altas cargas de trabalho, necessidade de concentração nas tarefas, de esconder as emoções negativas e de responder a várias demandas dos clientes).

Em um estudo de corte transversal, Valente ${ }^{30}$ encontrou, em população de 1.046 bancários dos estados do Pará e do Amapá, risco aumentado para desencadeamento de transtornos do humor, como depressão maior e outras depressões, relacionados ao alto esforço desprendido nas atividades de trabalho, alta demanda de trabalho e baixo controle do trabalhador sobre ele, assim como comprometimento excessivo e desequilíbrio esforço-recompensa no trabalho. Além desse quadro, a exposição a condições psicossociais diversas no trabalho esteve fortemente relacionada a altos níveis de esgotamento.

Silva e Barreto ${ }^{20}$ verificaram uma elevada prevalência de transtornos mentais menores em bancários brasileiros, reforçando a evidência entre a ocorrência desse tipo de agravo e as condições psicossociais desfavoráveis no trabalho bancário.

Também, doenças classificadas como crônico-degenerativas mostraram-se muito presentes entre os bancários.

Em estudo realizado no estado de Santa Catarina, Bittencourt e Vinholes ${ }^{\mathbf{3 1}}$ demonstraram que metade dos bancários apresentava risco futuro de desenvolvimento de Diabetes Mellitus do tipo II. Os autores apontam como uma das hipóteses dessa relação o fato de que 
Esses profissionais sofrem pressão psicológica para cumprimento de metas e conclusão rápida de tarefas, as quais necessitam de precisão e responsabilidade, além da possível existência

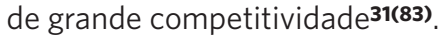

Estando submetidos constantemente a situações de 'estresse'. Hartwig, Machado e Hallal ${ }^{32}$ encontraram, em uma amostra de 55 bancários, obesidade em 13\% e sobrepeso em $55 \%$ deles. Sedentarismo foi verificado em $69 \%$ dos trabalhadores. Em pesquisa sobre sintomatologia musculoesquelética em bancários no estado de Santa Catarina, realizada no ano de 2004, Mergerner, Kehrig e Traebert ${ }^{\mathbf{1 8}}$ verificaram alta prevalência de queixas, que acometeram $72,8 \%$ dos trabalhadores pesquisados.

Salaroli et al. ${ }^{33}$, em uma população de 1410 bancários, constatou aumento da pressão arterial em $32,5 \%$ deles. Também encontrou alta prevalência de sobrepeso (36,9\%) e obesidade $(17,9 \%)$, o que associou à falta de atividade física e à atividade de trabalho essencialmente sedentária. Resultados semelhantes foram observados em estudo de Konradi et al. ${ }^{\mathbf{3 4}}$, no qual 1.561 bancários russos foram avaliados, sendo constatadas hipertensão em $35,2 \%$, obesidade abdominal em $45,6 \%$, com prevalência de síndrome metabólica em $21,5 \%$ dos examinados. Houve, também, relação entre a síndrome metabólica e baixa atividade física, tabagismo e abuso de álcool. Em 1.493 bancários na Índia, Momin et al. ${ }^{35}$ verificaram prevalência de hipertensão em 30,4\% da amostra, sendo maior entre gerentes (45.9\%).

\section{Conclusões}

Constatou-se com a presente revisão bibliográfica que os estudos demonstram significativas modificações do trabalho bancário nas últimas décadas. Sua atual forma de organização tem sido caracterizada pela precarização e intensificação do trabalho e pela incorporação de novas tecnologias, que geram dificuldades de adaptação para os trabalhadores.
Diversos estudos enfatizam que a reestruturação produtiva no setor bancário está relacionada ao aparecimento de efeitos negativos para a saúde dos trabalhadores.

$\mathrm{O}$ adoecimento foi relacionado, em grande parte dos estudos analisados, a instabilidade no emprego, ameaça de desemprego, individualismo exacerbado, exigências de performance baseadas na excelência, exigências constantes de qualificação, estímulo da competitividade entre colegas, redução dos espaços de representação dos trabalhadores, excesso ou falta de tarefas, pouco reconhecimento do trabalho, chefias autoritárias, pressões por produtividade, cobrança exacerbada de metas, maior pressão e controle dos trabalhadores, extensão da jornada de trabalho, entre tantos outros aspectos da organização contemporânea do trabalho.

Os estudos ainda evidenciam problemas derivados da vivência de situações de violência, como assaltos e sequestros, além dos tradicionais problemas relacionados à condição ergonômica inadequada dos postos de trabalho.

Alguns autores relacionam o adoecimento dos trabalhadores, também, a questões biomecânicas nas atividades laborais, como repetitividade de movimentos e mobiliário inadequado, que estariam relacionadas ao aparecimento de LER. Porém, na atualidade, além desses fatores biomecânicos, os estudos desvelam a importância de outros aspectos, como a organização do trabalho, no desencadeamento de LER/Dort.

As pesquisas têm demonstrado o aparecimento de uma gama de problemas de saúde, como sofrimento psíquico, alta prevalência de sedentarismo, obesidade, sobrepeso, diabetes, hipertensão arterial, uso de álcool.

Os transtornos mentais aparecem como um problema emergente de grande relevância. $\mathrm{Na}$ maioria dos estudos, o sofrimento psíquico e o adoecimento mental são relacionados à vivência de situações estressantes no trabalho. A alta prevalência de ansiedade e depressão, transtornos do estresse pós-traumático, burnout 
e esgotamento são relatados, além de um dramático aumento no número de suicídios.

A produção científica tem demonstrado que o aumento do sofrimento psíquico e do adoecimento mental entre os bancários é consequência das características que o processo de trabalho bancário vem assumindo.

$\mathrm{Na}$ maioria das pesquisas, no entanto, o estudo da organização do trabalho e seu papel no adoecimento dos bancários encontra-se insuficiente, exigindo maior investigação. Diversos fatores de risco são identificados, porém, sem o estabelecimento das relações de determinação que se estabelecem com a estrutura econômica da sociedade. Dessa lacuna resulta a indução de uma possível solução dos problemas com base na conscientização dos trabalhadores, de modo a adequarem sua postura ou relação com o trabalho, ocultando os limites que a eles se impõem, impedindo que tenham uma vida mais saudável.

Esta revisão atingiu o objetivo proposto, evidenciando que as pesquisas relacionam as condições de trabalho dos bancários a vários tipos de adoecimento dessa população trabalhadora. $\mathrm{O}$ aprofundamento dessa questão pode contribuir para a compreensão dos processos gerais de determinação das condições de vida relativos ao modo de produção vigente, determinantes dessa organização do trabalho e para a superação da condição deletéria à saúde na qual o trabalho bancário se encontra.

\section{Colaboradores}

Moronte EA (0000-0002-9682-3380)* e Albuquerque GSC (0000-0002-7544-412X)* contribuíram igualmente para a elaboração do manuscrito. 


\section{Referências}

1. Borges LH. Trabalho de caixa bancário, saúde mental e lesão por esforço repetitivo. In: Glina DMR, Rocha LE. Saúde Mental e Trabalho: da teoria à prática. São Paulo: Roca, 2010. p. 271-301.

2. Brasil. Ministério da Fazenda. $1^{\circ}$ Boletim Quadrimestral sobre Benefícios por incapacidade 2017. Adoecimento Mental e Trabalho A concessão de benefícios por incapacidade relacionados a transtornos mentais e comportamentais entre 2012 e 2016. Brasília, DF: Secretaria de Previdência; 2017.

3. Lacaz FAC. O campo Saúde do Trabalhador: resgatando conhecimentos e práticas sobre as relações trabalho-saúde. Cad. Saúde Pública. 2007; 23(4):757-766.

4. Geremias LM, Evangelista LF, Silva RC, et al. Prevalência do diabetes mellitus associado ao estresse ocupacional em trabalhadores bancários, Minas Gerais, Brasil. Rev Cuid [internet]. 2017 [acesso em 2019 out 10]; 8(3):1863-1874. Disponível em: http://www.scielo.org.co/scielo.php?script=sci_arttext\&pid=S2216$-09732017000301863 \& \operatorname{lng}=\mathrm{en}$.

5. Ferreira AP, Carvalho APC. Saúde do Trabalhador: Avaliação da Qualidade de Vida no Trabalho de Bancários. Cienc Trab. [internet]. 2017 [acesso em 2019 out 10]; 19(59):128-134. Disponível em: http://dx.doi. org/10.4067/S0718-24492017000200128.

6. Jaques AG, Ziliotto DM. As contingências do trabalho bancário: um estudo sobre os mecanismos de mediação e defesa do sofrimento. Interação em Psicologia. [internet]. 2017 [acesso em 2019 out 10]; 21(1):19818076. Disponível em: https://revistas.ufpr.br/psicologia/article/view/45308.

7. Silva JL, Navarro VL. Organização do trabalho e saúde de trabalhadores bancários. Rev. Latino-Am. Enfermagem [internet]. 2012 [acesso em 2019 out 10]; 20(2):226-234. Disponível em: http://www.scielo.br/scielo.php?script=sci_arttext\&pid=S0104$-11692012000200003 \& \operatorname{lng}=\mathrm{en}$.
8. Medeiros GF, Lucca SR, Pereira ACL, et al. Sequestros de bancários e seus impactos psicossociais e na saúde do trabalhador. Rev. Bras. Med. Trab. 2017; 15(1):42-53.

9. Silva LS, Pinheiro TMM, Sakurai E. Perfil do absenteísmo em um banco estatal em Minas Gerais: análise no período de 1998 a 2003. Ciênc. Saúde Colet. [internet]. 2008 [acesso em 2019 out 10]; 13(supl2):2049-2058. Disponível em: http://www. scielo.br/scielo.php?script=sci_arttext\&pid=S1413$-81232008000900009 \& \operatorname{lng}=$ pt.

10. Pichet SF, Ichikawa EY. Uso de ansiolíticos e antidepressivos por bancários: um estudo de representações sociais. Pesquisas e Práticas Psicossociais [internet]. 2015 [acesso em 2019 out 10]; 10(2):354-367. Disponível em: http://pepsic.bvsalud.org/scielo.php?script=sci arttext\&pid=S1809-89082015000200012\&lng=pt\&tl ng=pt.

11. Petarli GB, Salaroli LB, Bissoli NS, et al. Autoavaliação do estado de saúde e fatores associados: um estudo em trabalhadores bancários. Cad. Saúde Pública [internet]. 2015a [acesso em 2019 out 10]; 31(4):787-799. Disponível em: http://www.scielo.br/scielo.php?script=sci_arttext $\&$ pid $=$ S0102 $-311 X 2015000400787 \& \operatorname{lng}=\mathrm{en}$.

12. Murofuse NT, Marziale MHP. Mudanças no trabalho e na vida de bancários portadores de Lesões por Esforços Repetitivos: LER. Rev. Latino-Am. Enfermagem [internet]. 2001 [acesso em 2019 out 10]; 9(4):19-25. Disponível em: http://www.scielo.br/scielo.php?script=sci_arttext\&pid=S0104$-11692001000400004 \& \operatorname{lng}=\mathrm{en}$.

13. Coelho JAPM, Souza GHS, Cerqueira CLC, et al. Estresse como preditor da Síndrome de Burnout em bancários. Rev. psicol. organ. trab. [internet]. 2018 [acesso em 2019 out 10]; 18(1):306-315. Disponível em: http://pepsic.bvsalud.org/scielo.php?script=sci arttext\&pid=S1984-66572018000100005\&lng=pt\&n rm=iso. 
14. Santos MAF, Siqueira MVS, Mendes AM. Tentativas de Suicídio de Bancários no Contexto das Reestruturações Produtivas. Rev. de Administração Contemporânea. 2010 [acesso em 2021 mar 31]; 14(5):925-938. Disponível em: https://rac.anpad.org.br/index.php/ $\mathrm{rac} / \mathrm{article} / \mathrm{view} / 792$.

15. Santos MAF, Siqueira MVS. Considerações sobre trabalho e suicídio: um estudo de caso. Rev. bras. saúde ocup. [internet]. 2011 [acesso em 2019 out 10]; 36(123):71-83. Disponível em: http://www.scielo.br/scielo.php?script=sci_arttext\&pid=S0303$-76572011000100007 \& \operatorname{lng}=$ en.

16. Soares LR, Villela WV. O assédio moral na perspectiva de bancários. Rev. bras. saúde ocup. [internet]. 2012 [acesso em 2019 out 10]; 37(126):203-212. Disponível em: http://www.scielo.br/scielo.php?script=sci arttext\&pid=S0303-76572012000200003\&lng=en.

17. Scopel J, Oliveira PAB, Wehrmeister FC. LER/DORT na terceira década da reestruturação bancária: novos fatores associados? Rev. Saúde Pública [internet]. 2012 [acesso em 2019 out 10]; 46(5):875-885. Disponível em: http://www.scielo.br/scielo.php?script=sci_ arttext\&pid=S0034-89102012000500015\&lng=en.

18. Mergerner CR, Kehrig RT, Traebert J. Sintomatologia músculo-esquelética relacionada ao trabalho e sua relação com qualidade de vida em bancários do Meio Oeste Catarinense. Saúde soc. [internet]. 2008 [acesso em 2019 out 10]; 17(4):171-181. Disponível em: http://www.scielo.br/scielo.php?script=sci_ arttext\&pid=S0104-12902008000400017\&lng=en.

19. Silva LS, Barreto SM. Adverse psychosocial working conditions and minor psychiatric disorders among bank workers. BMC Public Health. 2010; (10):686693.

20. Silva LS, Barreto SM. Condições estressantes no trabalho e pior auto avaliação de saúde entre bancários. Rev. Saúde Pública [internet]. 2012 [acesso em 2019 out 10]; 46(3):407-416. Disponível em: http://www. scielo.br/scielo.php?script=sci_arttext\&pid=S0034$-89102012000300002 \& \operatorname{lng}=$ pt.
21. Paparelli R. Grupos de enfrentamento do desgaste mental no trabalho bancário: discutindo saúde mental do trabalhador no sindicato. Rev. bras. saúde ocup. [internet]. 2011 [acesso em 2019 out 10]; 36(123):139-146. Disponível em: http://www.scielo.br/scielo.php?script=sci_arttext $\&$ pid $=$ S0303$-76572011000100013 \& \operatorname{lng}=\mathrm{en}$.

22. Carrijo DCM, Navarro VL. LER e planos de demissão voluntária: trajetórias de dor e sofrimento entre bancários. Cad. psicol. soc. trab. [internet]. 2009 [acesso em 2019 out 10]; 12(2):157-171. Disponível em: http://pepsic.bvsalud.org/scielo.php?script=sci arttext\&pid=S1516-37172009000200003\&lng=pt\&n $\mathrm{rm}=\mathrm{iso}$.

23. Santos Júnior AV, Mendes AM, Araujo LKR. Experiência em clínica do trabalho com bancários adoecidos por LER/DORT. Psicol. cienc. prof. [internet]. 2009 [acesso em 2019 out 10]; 29(3):614-625. Disponível em: http://www.scielo.br/scielo.php?script=sci arttext\&pid=S1414-98932009000300014\&lng=en\&n $\mathrm{rm}=\mathrm{iso}$.

24. Ferreira MC, Seidl J. Mal-estar no trabalho: análise da cultura organizacional de um contexto bancário brasileiro. Psic.: Teor. e Pesq. [internet]. 2009 [acesso em 2019 out 10]; 25(2):245-254. Disponível em: http://www.scielo.br/scielo.php?script=sci arttext\&pid=S0102-37722009000200013\&lng=en\& nrm=iso.

25. Paiva CSDL, Borges LO. O ambiente de trabalho no setor bancário e o bem-estar. Psicol. estud. [internet]. 2009 [acesso em 2019 out 10]; 14(1):57-66. Disponível em: http://www.scielo.br/scielo.php?script=sci_ arttext\&pid=S1413-73722009000100008\&lng=en\&n $\mathrm{rm}=\mathrm{iso}$.

26. Kan D, Yu X. Occupational Stress, Work-Family Conflict and Depressive Symptoms among Chinese Bank Employees: The Role of Psychological Capital. Int. J. Environ. Res. Public Health [internet]. 2016 [acesso em 2019 out 10]; 13(1):134. Disponível em: https:// www.mdpi.com/1660-4601/13/1/134/pdf. 
27. Snorradóttir A, Vilhjálmsson R, Rafnsdóttir GL, et al. Financial crisis and collapsed banks: psychological distress and work related factors among surviving employees - a nation-wide study. Am J Ind Med. 2013; 56(9):1095-106. Disponível em: https:// pubmed.ncbi.nlm.nih.gov/23797952/.

28. Moraes PWT, Bastos AVB. Os Sintomas de LER/ DORT: um Estudo Comparativo entre Bancários com e sem Diagnóstico. Psicol. cienc. prof. [internet]. 2017 [acesso em 2019 out 10]; 37(3):624-637. Disponível em: http://www.scielo.br/scielo.php?script=sci arttext\&pid=S1414-98932017000300624\&lng=en\& nrm=iso.

29. Gaviraghi D, Antoni C, Amazarray MR, et al. Medicalização, uso de substâncias e contexto de trabalho em bancários do Rio Grande do Sul, Brasil. Rev. Psicol., Organ. Trab. [internet]. 2016 [acesso em 2019 out 10]; 16(1):61-72. Disponível em: http://pepsic.bvsalud.org/scielo.php?script=sci_arttext\&pid=S1984$-66572016000100006 \& \operatorname{lng}=p t \& n r m=$ iso

30. Valente MSS. Depressão e esgotamento profissional em bancários. [dissertação] [internet]. São Paulo: Universidade de São Paulo, 2014. 121 p. [acesso em 2019 out 10]; Disponível em: https://teses.usp.br/teses/ disponiveis/5/5137/tde-26112014-123022/pt-br.php.

31. Bittencourt A, Vinholes DB. Estimativa Do Risco Para Diabetes Mellitus Tipo 2 Em Bancários Da Cidade De Tubarão, Estado De Santa Catarina, Brasil. Scientia Médica [internet]. 2013 [acesso em 2019 out 10]; 23(2):82-89. Disponível em: https://dialnet.unirioja.es/descarga/articulo/5662556.pdf.

32. Hartwig TW, Machado CF, Hallal PC. Indicadores antropométricos e nível de atividade física de funcionários de banco. Revista Brasileira de Ciência e Movimento. 2009 [acesso em 2019 out 10]; 17(3):7075. Disponível em: http://cev.org.br/biblioteca/indicadores-antropometricos-nivel-atividade-fisica-funcionarios-banco.

33. Salaroli LB, Saliba RAD, Zandonade E, et al. Prevalence of metabolic syndrome and related factors in bank employees according to different defining criteria, Vitória/ES, Brazil. Clinics [internet]. 2013 [acesso em 2019 out 10]; 68(1):69-74. Disponível em: http://www. scielo.br/scielo.php?script=sci_arttext $\&$ pid=S1807$-59322013000100012 \& \operatorname{lng}=$ en.

34. Konradi AO, Rotar OP, Korostovtseva LS, et al. Prevalence of metabolic syndrome components in a population of bank employees from St. Petersburg, Russia. Metab Syndr Relat Disord. [internet]. 2011 [acesso em 2019 out 10]; 9(5):337-43. Disponível em: https:// pubmed.ncbi.nlm.nih.gov/21819220/.

35. Momin MH, Desai VK, Kavishwar AB. Study of socio-demographic factors affecting prevalence of hypertension among bank employees of Surat City. Indian J Public Health. [internet]. 2012 [acesso em 2019 out 10]; 56(1):44-8. Disponível em: https://pubmed.ncbi. nlm.nih.gov/22684172/.

36. Petarli GB, Zandonade E, Salaroli LB, et al. Estresse ocupacional e fatores associados em trabalhadores bancários, Vitória - ES, Brasil. Ciênc. Saúde Colet. [internet]. 2015b [acesso em 2019 out 10]; 20(12):39253934. Disponível em: https://www.scielosp.org/article/csc/2015.v20n12/3925-3934/pt/.

37. Marques GS, Giongo CR. Trabalhadores bancários em sofrimento: uma análise da literatura nacional. Rev. Psicol., Organ. Trab. [internet]. 2016 [acesso em 2019 out 10]; 16(3):220-247. Disponível em: http://pepsic.bvsalud.org/scielo.php?script=sci arttext\&pid=S1984-66572016000300002\&lng=pt\& nrm=iso.

38. Mello PG, Caminha RM, Lorenzzoni PL, et al. Considerações clínicas sobre a psicoterapia cognitivo-comportamental de bancários com Transtorno de Estresse Pós-Traumático. Contextos Clínic. [internet]. 2011 [acesso em 2019 out 10]; 4(1):1-7. Disponível em: http://pepsic.bvsalud.org/scielo.php?script=sci arttext\&pid=S1983-34822011000100001\&lng=pt\&nr $\mathrm{m}=$ iso.

39. Martinez JFN, Júnior EM. Os limites da ginástica laboral para compreensão dos determinantes de saú- 
de de trabalhadores bancários. Pensar a prática [internet]. 2012 [acesso em 2019 out 10]; 15(3):610-624. Disponível em: https://revistas.ufg.br/fef/article/ view/13273.

40. Oltramari AP, Grisci CLI, Weber L. Carreira e relações familiares: dilemas de executivos bancários. Rev. Mal-Estar Subj. [internet]. 2011 [acesso em 2019 out 10]; 11(1):100-133. Disponível em: http://pepsic.bvsalud.org/scielo.php?script=sci_arttext\&pid=S1518$-61482011000100005 \& \operatorname{lng}=$ pt\&nrm=iso.
41. Pavão P. La lucha de los sindicatos de bancarios de Brasil contra el acoso moral. Salud trab. [internet]. 2013 [acesso em 2019 out 10]; 21(1):31-40. Disponível em: http://ve.scielo.org/scielo.php?script=sci arttext\&pid=S1315-01382013000100004\&lng=es.

Recebido em 14/10/2019

Aprovado em 06/08/2020

Conflito de interesses: inexistente

Suporte financeiro: não houve 